\title{
Erratum to: Summation by Parts Operators for Finite Difference Approximations of Second-Derivatives with Variable Coefficients
}

\author{
Ken Mattsson
}

Published online: 31 December 2011

(C) Springer Science+Business Media, LLC 2011

\section{Erratum to: J Sci Comput \\ DOI 10.1007/s10915-011-9525-z}

In the original publication, the author's affiliation contained the wrong country name. "Finland" should read "Sweden".

The third-order accurate boundary derivative operator $S$ on page 18 in Appendix A.2 should read:

$$
S=\frac{1}{h}\left[\begin{array}{ccccccc}
-\frac{11}{6} & 3 & -\frac{3}{2} & \frac{1}{3} & & & \\
& 1 & & & & & \\
& & & \ddots & & & \\
& & & -\frac{1}{3} & \frac{3}{2} & -3 & \frac{11}{6}
\end{array}\right] .
$$

The online version of the original article can be found under doi:10.1007/s10915-011-9525-z. 